\title{
Stigma rises despite antiretroviral roll-out: A longitudinal analysis in South Africa ${ }^{\text {ts }}$
}

\author{
Brendan Maughan-Brown* \\ AIDS and Society Research Unit, University of Cape Town, Private Bag, Rondebosch, 7701, Cape Town, South Africa
}

\section{A R T I C L E I N F O}

Article history:

Available online 4 November 2009

Keywords:

South Africa

HIV

Stigma

Antiretroviral treatment (ART)

AIDS

\begin{abstract}
A B S T R A C T
Stigma is a recognised problem for effective prevention, treatment, and care of HIV/AIDS. However, few studies have measured changes in the magnitude and character of stigma over time. This paper provides the first quantitative evaluation in Africa of the changing nature of stigma and the potential determinants of these changes. More specifically, it evaluates the dynamic relationship between stigma and (1) increased personal contact with people living with HIV/AIDS and (2) knowing people who died of AIDS. Panel survey data collected in Cape town 2003 and 2006 for 1074 young adults aged 14-22 years were used to evaluate changes in three distinct dimensions of stigma: behavioural intentions towards people living with HIV/AIDS; instrumental stigma; and symbolic stigma. Individual fixed effects regression models are used to evaluate factors that influence stigma over time. Each dimension of stigma increased in the population as a whole, and for all racial and gender sub-groups. Symbolic stigma increased the most, followed by instrumental stigma, while negative behavioural intentions showed a modest increase. Knowing someone who died of AIDS was significantly associated with an increase in instrumental stigma and symbolic stigma, while increased personal contact with people living with HIV/AIDS was not significantly associated with any changes in stigma. Despite interventions, such as public-sector provision of antiretroviral treatment (which some hoped would have reduced stigma), stigma increased among a sample highly targeted with HIV-prevention messages. These findings emphasise that changes in stigma are difficult to predict and thus important to monitor. They also indicate the imperative for renewed efforts to reduce stigma, perhaps through interventions to weaken the association between HIV/AIDS and death, to reduce fear of HIV/AIDS, and to recast HIV as a chronic manageable disease.
\end{abstract}

(C) 2009 Elsevier Ltd. All rights reserved.

\section{Introduction}

HIV-related stigma is universal, pervading all regions of the globe (Aggleton \& Parker, 2002). Stigma can, among other things, discourage people from being tested, impede access to treatment and other health care services, undermine adherence to treatment, and discourage disclosure to sexual partners (Herek, Capitanio, \& Widaman, 2003; Kalichman \& Simbayi, 2006; Rao, Kekwaletswe, Hosek, Martinez, \& Rodriguez, 2007; Wolfe et al., 2006). Combating stigma is thus widely recognised as a key ingredient in the struggle against HIV and AIDS, and for improvements in public health in general (Aggleton, Parker, \& Maluwa, 2003). This is especially

\footnotetext{
is I thank Nicoli Nattrass, David Maughan-Brown, Rebecca Maughan-Brown and Atheendar Venkataramani for comments on drafts of this paper. I would like to acknowledge funding from the AIDS and Society Research Unit at the University of Cape Town, Yale University and the Health Economics and HIV/AIDS Research Division at the University of KwaZulu-Natal.

* Tel.: +27 1203 5007385; fax: +27 216504657 .

E-mail address: brendan.maughanbrown@gmail.com
}

pertinent in sub-Saharan Africa, the epicenter of the disease, where prevalence rates are the highest in the world (UNAIDS, 2006; Whiteside, 2008).

However, despite widespread awareness of the negative impact of stigma, advances in public health programmes to address stigma have been comparatively slow and unsystematic (van Brakel, 2006). In particular, very little is known about how stigma changes over time and the factors that might influence such change. This information is important as researchers designing stigma intervention strategies need to be cognisant of, and responsive to, the changing social context for people living with HIV or AIDS (PLWHA). As the epidemic matures the social context will change as a result of social responses to HIV prevention and treatment interventions. Research into the dynamics of such changes is rare (see Herek \& Capitanio, 1999 for one example in the United States). There is clearly an urgent need to measure changes in the magnitude and character of social attitudes towards PLWHA and evaluate how these attitudes shift in response to stigma, treatment and prevention interventions (Weiss, Ramakrishna, \& Somma, 2006). 
Stigma refers to a social process through which individuals are devalued on the basis of particular negatively perceived characteristics or status. HIV-related stigma is amenable to change because the meanings attached to HIV/AIDS and its symbolic representations shift over time. The development of effective treatment has, for example, been seen as contributing to the reduction in stigmatising attitudes and behaviours towards certain diseases (Weiss \& Ramakrishna, 2006). Highly Active Antiretroviral Therapy (HAART) has the potential to change the perception of AIDS as a death sentence, and thereby reduce stigma (PrestonWhyte, 2003). Access to HAART is believed, for example, to have lessened HIV-related stigma in Haiti (Farmer et al., 2001), among adolescents in Brazil (Abadía-Barrero \& Castro, 2005), and in villages in rural China (Cao, Sullivan, Wi, \& the China CIPRA Project 2 Team, 2006).

South Africa's public-sector HAART programme was launched in most provinces in 2004 and had been piloted in the Western Cape since 2001. By 2006, HAART coverage in the Western Cape was at $55.7 \%$ of the number of people estimated to need HAART (Nattrass, 2007, p. 131).

One would expect this to have had some effect on reducing HIVrelated stigma over time - especially between 2003 and 2006. However, Herek (2002) warns that while disease stigma historically decreases as the disease is better understood and as treatment becomes available, this appears not always to be the case with regard to HIV/AIDS. Herek suggests that the general public remains poorly informed about HIV and that the scientific information about HIV is simply not trusted by some sectors of the public, which are perhaps influenced by political figures who openly question the science around antiretrovirals.

The efficacy of HAART to reduce stigma may also have been undermined by the lack of full HAART coverage in South Africa, which has resulted in continual increases in AIDS deaths. AIDSrelated deaths have continued to rise but at a slower rate than before the introduction of HAART. Nonetheless there remains an association between HIV and death which might fuel stigma.

Another theory is that levels of stigma will be associated with HIV-prevalence levels: based on the contact hypothesis (see Herek \& Capitanio, 1997) prejudice is believed to decrease with increased direct contact with members of the stigmatised group. A study conducted in rural China found supporting evidence for this theory: villages where HIV prevalence was high were associated with lower levels of stigma (Cao et al., 2006). In Kenya, Hamra et al. also found that personal acquaintance with PLWHA was associated with fewer manifestations of HIV-related stigma (Hamra, Ross, Orrs, \& D'Agostino, 2006). Given that HIV prevalence has increased in the Western Cape since 2000 (Actuarial Society of South Africa, 2005) stigma should, accordingly, have decreased as a result. This would be the case among the black population in particular as prevalence rates among this group increased the most and presumably are associated with greater personal contact.

However, Almeleh's (2006) finding that PLWHA in South Africa generally do not disclose until they are manifestly sick raises the possibility that the increase in the number of AIDS-sick people, especially among blacks (Actuarial Society of South Africa, 2005), results in more people becoming aware of the negative aspects of HIV, and this could result in the perpetuation of stigma. The South African National HIV Prevalence, HIV Incidence, Behaviour and Communication Survey in 2005 found some evidence for this with a positive correlation between negative attitudes and close contact to PLWHA (Shisana et al., 2005).

It is clear that the social context surrounding HIV/AIDS in the Western Cape has changed in the past few years, as a result of increasing numbers of AIDS-related deaths on the one hand and drastic improvements in health due to the HAART roll-out on the other (Coetzee et al., 2004). It is not clear, however, how stigmatising attitudes and behaviours have changed in response. This paper fills an important gap in research on HIV-related stigma by using individual-level panel data to discern and quantify trends in stigma among young adults in Cape Town, and by examining potential determinants of these changes.

\section{Method}

\section{Sample}

This paper uses panel data (i.e. data where multiple cases were observed at two or more time periods) from the Cape Area Panel Study (CAPS). CAPS is a longitudinal study of young adults in Cape Town. The first wave of CAPS, conducted in 2002, interviewed 4752 young adults, aged between 14 and 22 years. CAPS has a complex survey design. The sample was stratified by race: black, coloured, and white ('coloured' is a common and socially acceptable term in South Africa for individuals of mixed race). The primary sampling units were the enumeration areas, comprising clusters of households drawn from the 1996 general census. Four hundred and forty units, about 10\% of the enumeration areas in Cape Town in the 1996 census, were selected based on probabilities proportional to size. Simple random sampling, using aerial photographs of each enumeration area, was then used to select 25 households within each unit. Finally, a maximum of three individuals between the ages of 14 and 22 were selected from each household. It was uncommon for more than three individuals to reside in one household, but when it occurred, the three individuals with the most recent birthday were selected. The household response rate was $75 \%$ and, conditional on the household having been interviewed, the response rate for young adults was $90 \%$. This wave of CAPS collected demographic, behavioural, and attitudinal information.

In 2003, the second wave of CAPS re-interviewed 1371 of the original respondents - resource constraints prevented the entire sample being interviewed. Selection of respondents for the second wave was based on systematic selection of clusters within the black and coloured strata, and systematic selection of individuals in the white stratum. In each case a random starting point was chosen and every third unit was selected. The response rate for the second wave was $83 \%$. The second wave included a module of questions probing attitudes and behavioural intentions towards PLWHA.

Table 1 displays the key demographic information of the CAPS 2003 sample. More than half the sample was black and less than $10 \%$ white. The sample was slightly biased in favour of women. Most respondents had completed at least grade 7 and the majority was still in secondary school. The majority lived in households with a per capita household income of less than R876 (US\$118.1) per month. The significant majority of respondents (86\%) were affiliated to a religious organisation.

The fourth survey wave of 2006 re-interviewed 1075 of the 1371 second wave respondents. CAPS respondents for each wave of data collection gave written informed consent. Ethical approval for CAPS was given by the University of Cape Town and the University of Michigan.

\section{Measurement of stigma}

The 2003 and 2006 CAPS included eight stigma questions (see Table 2). These questions were selected to cover behavioural intentions towards PLWHA along with instrumental stigma (i.e. negative judgement based on inflated fears of infection) and symbolic stigma (i.e. negative moral judgement) (see MaughanBrown, 2006). Factor analysis of the 2003 responses confirmed that 
Table 1

CAPS 2003 sample characteristics.

\begin{tabular}{|c|c|c|c|c|}
\hline & & $n$ & Percent & Mean \\
\hline All respondents & & 1371 & $100 \%$ & \\
\hline Race & $\begin{array}{l}\text { Black } \\
\text { Coloured } \\
\text { White }\end{array}$ & $\begin{array}{l}782 \\
460 \\
128\end{array}$ & $\begin{array}{r}57 \% \\
34 \% \\
9 \% \\
100 \%\end{array}$ & \\
\hline Gender & $\begin{array}{l}\text { Men } \\
\text { Women }\end{array}$ & $\begin{array}{l}625 \\
746\end{array}$ & $\begin{array}{r}46 \% \\
54 \% \\
100 \%\end{array}$ & \\
\hline Education & $\begin{array}{l}<\text { Grade } 8 \\
\text { Grade } 8-11 \\
\text { Grade } 12 \\
\text { Some tertiary }\end{array}$ & $\begin{array}{r}226 \\
872 \\
204 \\
66\end{array}$ & $\begin{array}{r}16 \% \\
64 \% \\
15 \% \\
5 \% \\
100 \%\end{array}$ & 9.63 \\
\hline Income & $\begin{array}{l}\text { per capita household (pcy) } \\
\text { Less than average pcy } \\
\text { More than average pcy }\end{array}$ & $\begin{array}{r}1028 \\
343\end{array}$ & $\begin{array}{r}75 \% \\
25 \% \\
100 \%\end{array}$ & $\operatorname{R876}(\$ 118.1)^{a}$ \\
\hline Religion & $\begin{array}{l}\text { No } \\
\text { Yes }\end{array}$ & $\begin{array}{r}185 \\
1173\end{array}$ & $\begin{array}{r}14 \% \\
86 \% \\
100 \%\end{array}$ & \\
\hline
\end{tabular}

Note: The total number of respondents differs between variables due to missing data.

a Exchange of 1 United States dollar = 7.42 South African Rands as on 1 July, 2003.

each of the eight questions contributed to one of the three categories: behavioural intentions, instrumental stigma and symbolic stigma (Maughan-Brown, 2006). Response options for the eight stigma questions were "definitely yes", "probably yes", "probably no" and "definitely no", coded from 1 (low stigma) to 4 (high stigma). An increase in "don't know" responses raised a difficult methodological question about how to use this information. The easiest solution was to exclude the "don't know" responses. This seemed unsatisfactory because someone who, for example, thinks in 2003 that HIV is definitely not a punishment for "sleeping around," but in 2006 is uncertain ("don't know") could reasonably be regarded as having developed a more negative attitude. In other words, the "don't know" responses have valuable content that should be captured in any empirical work. Accordingly, the analyses coded the "don't know" response as a mid-point (2.5) between yes and no. Importantly, sensitivity analyses excluding the "don't know" option yielded results with the same sign and significance, and only marginal changes in the coefficients.

Each of these questions was translated into the first language of the respondents and administered in face-to-face interviews. Focus groups were conducted to evaluate the interpretability of the questions within different population groups and the validity of the translations. The questions were clearly understood by everyone and interpretations were consistent with the intended construct.
In order to examine trends in HIV-related stigma, descriptive statistics were calculated for the eight stigma questions for both survey waves. $T$-tests (paired) were then used to assess differences in the average scores for each question. The Stuart Maxwell test for homogeneity was then conducted to evaluate whether the stigma trends identified represented real changes in stigma or systematic survey effects (i.e. when changes in the survey method affect responses). Finally, an attrition test was done to examine any potential bias caused by attrition between the survey waves. Potential determinants of stigma, in particular whether an individual reported meeting someone living with HIV or knowing someone who died of AIDS, were assessed using individual fixed effects regression models. Individual random effects models were also considered, but the Hausman test suggested that they were inconsistent and gave biased parameter estimates.

\section{Analysis \& results}

The analysis \& results section of this paper is divided into 3 parts: (1) changes in reported stigma; (2) changes in stigma by gender, race and age; and (3) determinants of stigma transitions.

\section{Changes in reported stigma}

This section evaluates transitions that occurred within the panel between 2003 and 2006 (i.e. among the individuals who were interviewed in both the surveys). Table 3 provides a summary of the changes in responses to the stigma questions between 2003 and 2006. The first column of percentages shows that in 2003, at baseline, relatively few respondents expressed negative behavioural intentions towards PLWHA, while significantly more respondents reported instrumental and symbolic stigma. The last column, 'stigma change', shows the difference between the percentage of respondents reporting an increase in stigma and those reporting a decrease.

Table 3 shows a net increase in the percentage of respondents reporting stigma for every question, except Question 3. These changes resulted in a significant increase in the mean scores for the majority of items and no item showed a significant decrease, using t-tests. The behavioural intentions items (which showed low levels of stigma in 2003) changed the least, with a significant increase for Question 1 only. In other words, on average, respondents were more likely to say they would not remain friends with a PLWHA in 2006 than 2003, but attitudes were unchanged about pupils attending school and buying fresh vegetables from an HIV-positive shopkeeper. Two of the instrumental stigma questions (Questions 4 and 5) showed a significant increase in stigma between 2003 and 2006, while the increase for Question 6 was non-significant. Both the symbolic stigma questions showed significant increases in stigma. The largest difference is noted for Question 7, with almost a quarter of respondents reporting an increase in stigma. Finally,

Table 2

Stigma questions asked in 2003 and 2006 Cape Area Panel Study.

\begin{tabular}{|c|c|}
\hline $\begin{array}{l}\text { Please respond to the following questions by answering "Yes" or "No". If you are not sure, chose the "Probably Yes" or } \\
\text { "Probably No" response. If you are quite sure chose the "Definitely Yes" or "Definitely No" response. } \\
\text { Interviewer: Do not read the "don't know" option }\end{array}$ & Dimension of stigma \\
\hline $\begin{array}{l}\text { 1. Imagine that you find out that one of your friends is HIV infected. Would you still be friends with them? } \\
\text { 2. If you knew that a shopkeeper had HIV/AIDS, would you buy fresh vegetables from him or her? } \\
\text { 3. Do you think a school pupil with HIV should be allowed to attend school? } \\
\text { 4. Would you drink from the same bottle of water as an HIV infected friend? } \\
\text { 5. Would you rather not touch someone with HIV/AIDS because you are scared of infection? } \\
\text { 6. Do you worry that HIV is much easier to catch than we are told? } \\
\text { 7. Do you think HIV/AIDS is a punishment for sleeping around? } \\
\text { 8. Do you think that many people who get HIV infected through sex have only themselves to blame? }\end{array}$ & $\begin{array}{l}\text { Behavioural intentions } \\
\text { Behavioural intentions } \\
\text { Behavioural intentions } \\
\text { Instrumental stigma } \\
\text { Instrumental stigma } \\
\text { Instrumental stigma } \\
\text { Symbolic stigma } \\
\text { Symbolic stigma }\end{array}$ \\
\hline
\end{tabular}


Table 3

HIV-stigma changes between 2003 and 2006.

\begin{tabular}{|c|c|c|c|c|c|}
\hline & \multirow{2}{*}{$\begin{array}{l}\text { Stigma } \\
2003\end{array}$} & \multicolumn{2}{|c|}{ Transition } & \multirow{2}{*}{$\begin{array}{l}\text { Stigma } \\
2006\end{array}$} & \multirow{2}{*}{$\begin{array}{l}\text { Stigma } \\
\text { change }\end{array}$} \\
\hline & & - & $0+$ & & \\
\hline $\begin{array}{l}\text { 1. Imagine that you find out that one of } \\
\text { your friends is HIV infected. Would } \\
\text { you still be friends with them? } \\
\text { (Behavioural intentions) }\end{array}$ & $2 \%$ & $6 \%$ & $77 \% 17 \%$ & $13 \%$ & $+11 \% * * *$ \\
\hline $\begin{array}{l}\text { 2. If you knew that a shopkeeper had } \\
\text { HIV/AIDS, would you buy fresh } \\
\text { vegetables from him or her? } \\
\text { (Behavioural intentions) }\end{array}$ & $16 \%$ & $22 \%$ & $53 \% 26 \%$ & $20 \%$ & $+4 \%$ \\
\hline $\begin{array}{l}\text { 3. Do you think a school pupil with HIV } \\
\text { should be allowed to attend school? } \\
\text { (Behavioural intentions) }\end{array}$ & $7 \%$ & $12 \%$ & $77 \% 11 \%$ & $6 \%$ & $-1 \%$ \\
\hline $\begin{array}{l}\text { 4. Would you drink from the same } \\
\text { bottle of water as an HIV infected } \\
\text { friend? (Instrumental stigma) }\end{array}$ & $21 \%$ & $18 \%$ & $42 \% 40 \%$ & $43 \%$ & $+22 \%^{* * *}$ \\
\hline $\begin{array}{l}\text { 5. Would you rather not touch } \\
\text { someone with HIV/AIDS because } \\
\text { you are scared of infection? } \\
\text { (Instrumental stigma) }\end{array}$ & $20 \%$ & $21 \%$ & $45 \% 35 \%$ & $34 \%$ & $+14 \%^{* * *}$ \\
\hline $\begin{array}{l}\text { 6. Do you worry that HIV is much } \\
\text { easier to catch than we are told? } \\
\text { (Instrumental stigma) }\end{array}$ & $54 \%$ & $35 \%$ & $28 \% 37 \%$ & $56 \%$ & $+2 \%$ \\
\hline $\begin{array}{l}\text { 7. Do you think HIV/AIDS is } \\
\text { a punishment for sleeping around? } \\
\text { (Symbolic stigma) }\end{array}$ & $29 \%$ & $21 \%$ & $34 \% 45 \%$ & $53 \%$ & $+24 \% * * *$ \\
\hline $\begin{array}{l}\text { 8. Do you think that many people who } \\
\text { get HIV infected through sex have } \\
\text { only themselves to blame? } \\
\text { (Symbolic stigma) }\end{array}$ & $42 \%$ & $26 \%$ & $32 \% 42 \%$ & $58 \%$ & $+16 \% * * *$ \\
\hline
\end{tabular}

Note: ${ }^{* * *} p<0.01$ significance level.

'-'; ' 0 ' \& '+' transitions represent the percentage of respondents in 2006 who reported less stigma, equal levels and more stigma respectively.

the 'transition' columns reveal that although there were overall increases in stigma, many respondents also reported a decrease in stigma. The Stuart Maxwell test for homogeneity of the marginal distributions was used to confirm that change did not reflect survey administration effects.

Attrition of 296 responders from 2003 was examined to see if the substantive findings of this study would have changed had these respondents remained in the study and reported a significant decrease in stigma. Attrition did not affect results.

\section{Changes in stigma by gender, race and age}

Variation in stigma over time was examined in relation to various predictors. Composite scores for the three stigma indices, based on face validity and confirmatory factor analysis, provided an indicator of behavioural intentions ( $\alpha=0.55$ at baseline), instrumental stigma ( $\alpha=0.48$ at baseline); and symbolic stigma ( $\alpha=0.57$ at baseline). Cronbach's alpha scores within this range were expected as the items measured different aspects of a complex social phenomenon and hence a high degree of internal consistency was unlikely (Terwee et al., 2007). Punishment and blame, for example, are two different aspects within the construct of symbolic stigma.

Convergent validity of the indices was evaluated via correlation analysis of the extent to which they related to each other. The positive correlations were all significant $(p<0.01)$.

Table 4 displays $t$-test results for the difference in average scores between 2003 and 2006 and the percentage of respondents reporting a change in stigma by gender, race and age. Age is split into those who were 18 or younger in 2003 (48\% of respondents) and those who were 19 or older in 2003 (52\% of respondents) with a view to roughly equal cohort sizes.
Table 4

Mean change in stigma scores from 2003 to 2006 by gender, race and age.

\begin{tabular}{llll}
\hline & $\begin{array}{l}\text { Behaviour } \\
\text { intentions }\end{array}$ & $\begin{array}{l}\text { Instrumental } \\
\text { stigma }\end{array}$ & $\begin{array}{l}\text { Symbolic } \\
\text { stigma }\end{array}$ \\
\hline Women & +0.14 & $+0.43^{* *}$ & $+0.88^{* *}$ \\
Men & +0.21 & $+0.84^{* *}$ & $+0.69^{* *}$ \\
Blacks & +0.11 & $+0.61^{* *}$ & $+1.14^{* *}$ \\
Coloureds & $+0.26^{* *}$ & $+0.64^{* *}$ & $+0.36^{* *}$ \\
Whites & +0.14 & $+0.60^{* *}$ & +0.23 \\
18 years or under in & +0.10 & $+0.64^{* *}$ & $+0.84^{* *}$ \\
$\quad$ 2003 & & & \\
Over 18 years in 2003 & $+0.25^{* *}$ & $+0.60^{* *}$ & $+0.74^{* *}$ \\
\hline
\end{tabular}

Note: ${ }^{*} p<0.05$; ${ }^{* *} p<0.01$; positive score means more stigma.

Table 4 reveals that although a significant minority reported a decrease in stigma, an average increase in stigma was reported by all groups for each dimension of stigma. Although the increases in averages were relatively small - the percentage increases in the average instrumental and symbolic stigma for men, for example, were $14 \%$ and $16 \%$ respectively - the table indicates an upward trend.

With respect to gender, men showed a greater average increase for instrumental stigma than women, while symbolic stigma increased more among women than men. In other words, fear of infection increased for everyone, but the increase was greater among men; and negative moral judgements increased for everyone, but the increase was greater among women. The increase in average negative behavioural intentions was non-significant among women and only marginally significant among men.

By race, coloureds were the only group to express an increase in negative behavioural intentions that was statistically significant. All groups showed a similar increase in instrumental stigma. Symbolic stigma increased most significantly among blacks and also among coloureds, while the increase among whites was non-significant. The most notable change in stigma by race was the increase in symbolic stigma among blacks.

Relatively small variation was found between the age groups for each dimension of stigma. The older group reported a significant increase in negative behavioural intentions, while the increase for the younger group was non-significant. On the other hand, the younger group reported slightly larger increases in both instrumental stigma and symbolic stigma compared to the older group.

\section{Determinants of stigma transitions}

One potential determinant of change in stigmatising attitudes and behavioural intentions was knowing someone living with HIV/ AIDS or someone who had died of AIDS. In this regard, the sample was restricted to respondents who reported in 2002 not knowing someone living with HIV/AIDS or someone who had died of AIDS. The impact on stigma of subsequently meeting someone living with HIV or knowing someone who died of AIDS between the baseline 2002 and 2006 was assessed. Because the stigma questions were

Table 5

New contact with HIV/AIDS between 2002 and 2006.

\begin{tabular}{|c|c|c|}
\hline & $\begin{array}{l}\text { Number (\%) of respondents } \\
\text { who first met PLWHA } \\
\text { between } 2002 \text { \& } 2006\end{array}$ & $\begin{array}{l}\text { Number (\%) of respondents } \\
\text { who first knew someone to } \\
\text { die of AIDS between } 2002 \& 2006\end{array}$ \\
\hline Black & $124(36 \%)$ & $149(43 \%)$ \\
\hline Coloured & $26(8 \%)$ & $21(7 \%)$ \\
\hline White & $5(9 \%)$ & $4(7 \%)$ \\
\hline Total & 155 & 174 \\
\hline
\end{tabular}


first asked in 2003, experiencing these events between 2002 and 2003 could have undermined the effect.

Table 5 displays the percentage of CAPS respondents who reported either experience between 2002 and 2006. The table shows that significantly more young black adults than either whites or coloureds living in Cape Town reported knowing PLWHA (36\%) and knowing someone who died of AIDS (43\%) between 2002 and 2006. After excluding missing data, there were insufficient observations to conduct the analysis for any race group except blacks. Three different dependent variables were used: behavioural intentions, instrumental stigma and symbolic stigma. The main independent variables of interest were: contact with PLWHA, knowing someone who died of AIDS, and both experiences. The following variables controlled for other factors that might influence changes in stigma: increase in years of education, survey year, 2003 HIV knowledge, 2003 general bigotry or prejudiced attitudes, age, and gender.

The model for behavioural intentions also included instrumental stigma and symbolic stigma as independent variables. This is because individuals who expressed these stigmatising attitudes in 2003 were more likely to express negative behavioural intentions towards PLWHA. The analysis presented here tests whether changes in instrumental stigma or symbolic stigma affected changes in behavioural intentions.

Table 6 displays the individual fixed effects regression results. The results indicate that after controlling for the other variables in the model, having met someone living with HIV/AIDS between 2003 and 2006 was not a significant predictor of changes in any dimension of stigma. Controlling for everything else, personally knowing someone who had died, or was thought to have died of HIV/AIDS, was associated with increases in instrumental stigma

\section{Table 6}

Beta coefficients (SE) from fixed effects regression models for changes in stigma among young black individuals in Cape Town.

\begin{tabular}{|c|c|c|c|}
\hline & $\begin{array}{l}\text { Behavioural } \\
\text { intentions }\end{array}$ & $\begin{array}{l}\text { Instrumental } \\
\text { stigma }\end{array}$ & $\begin{array}{l}\text { Symbolic } \\
\text { stigma }\end{array}$ \\
\hline Know someone with HIV & $\begin{array}{l}0.48 \\
{[0.38]}\end{array}$ & $\begin{array}{l}0.71 \\
{[0.64]}\end{array}$ & $\begin{array}{l}0.42 \\
{[0.48]}\end{array}$ \\
\hline Know someone who died of AIDS & $\begin{array}{l}-0.49 \\
{[0.35]}\end{array}$ & $\begin{array}{l}0.66^{*} \\
{[0.39]}\end{array}$ & $\begin{array}{l}1.20^{* * *} \\
{[0.42]}\end{array}$ \\
\hline $\begin{array}{l}\text { Know someone with HIV and know } \\
\text { someone who died of AIDS }\end{array}$ & $\begin{array}{l}-0.18 \\
{[0.53]}\end{array}$ & $\begin{array}{l}-0.74 \\
{[0.78]}\end{array}$ & $\begin{array}{l}-0.89 \\
{[0.66]}\end{array}$ \\
\hline Increased education & $\begin{array}{l}0.05 \\
{[0.12]}\end{array}$ & $\begin{array}{l}0.07 \\
{[0.21]}\end{array}$ & $\begin{array}{l}-0.32^{* *} \\
{[0.15]}\end{array}$ \\
\hline 2003 HIV knowledge & $\begin{array}{l}0.16 \\
{[0.11]}\end{array}$ & $\begin{array}{l}0.38^{* * *} \\
{[0.13]}\end{array}$ & $\begin{array}{l}0.25^{* * *} \\
{[0.09]}\end{array}$ \\
\hline 2003 general bigotry & $\begin{array}{l}0.01 \\
{[0.01]}\end{array}$ & $\begin{array}{l}-0.01 \\
{[0.01]}\end{array}$ & $\begin{array}{l}-0.02^{* *} \\
{[0.01]}\end{array}$ \\
\hline Age & $\begin{array}{l}0.09 \\
{[0.06]}\end{array}$ & $\begin{array}{l}-0.03 \\
{[0.17]}\end{array}$ & $\begin{array}{l}-0.07 \\
{[0.06]}\end{array}$ \\
\hline Gender (base = women) & $\begin{array}{l}-0.16 \\
{[0.26]}\end{array}$ & $\begin{array}{l}0.94^{* * *} \\
{[0.37]}\end{array}$ & $\begin{array}{l}0.45 \\
{[0.29]}\end{array}$ \\
\hline Survey year & $\begin{array}{l}-2.69^{* *} \\
{[1.29]}\end{array}$ & $\begin{array}{l}-1.85 \\
{[1.98]}\end{array}$ & $\begin{array}{l}1.45 \\
{[1.37]}\end{array}$ \\
\hline Change in instrumental stigma & $\begin{array}{l}0.17^{* * *} \\
{[0.05]}\end{array}$ & $\begin{array}{l}\mathrm{n} / \mathrm{a} \\
\mathrm{n} / \mathrm{a}\end{array}$ & $\begin{array}{l}\mathrm{n} / \mathrm{a} \\
\mathrm{n} / \mathrm{a}\end{array}$ \\
\hline Change in symbolic stigma & $\begin{array}{l}-0.06 \\
{[0.06]}\end{array}$ & $\begin{array}{l}\mathrm{n} / \mathrm{a} \\
\mathrm{n} / \mathrm{a}\end{array}$ & $\begin{array}{l}\mathrm{n} / \mathrm{a} \\
\mathrm{n} / \mathrm{a}\end{array}$ \\
\hline $\mathrm{n}$ & 607 & 608 & 610 \\
\hline R-squared & 0.10 & 0.12 & 0.28 \\
\hline Prob $>F$ & 0.000 & 0.000 & 0.000 \\
\hline
\end{tabular}

Note: ${ }^{*} p<0.101 ;{ }^{* *} p<0.05 ;{ }^{* * *} p<0.01$. and symbolic stigma. In addition, increased negative behavioural intentions were significantly associated with increased instrumental stigma. In other words, increased fear of infection appeared to decrease tolerance towards PLWHA.

Another interesting finding displayed in Table 6 involves levels of HIV knowledge in 2003. The regression showed that, controlling for the other variables in the model, individuals with better knowledge of HIV transmission in 2003 showed greater increases in instrumental stigma and symbolic stigma between 2003 and 2006. Finally, controlling for the other variables, men showed greater increases in instrumental stigma than women.

\section{Discussion}

Overall, stigma increased among young adults in Cape Town between 2003 and 2006. Behavioural intentions became slightly more negative over time, but overall levels of discriminatory intentions remained relatively low. This does not necessarily mean, however, that discrimination (or enacted stigma) towards PLWHA is not a problem, or is not increasing, as the more subtle manifestations of enacted stigma, such as gossip or hand signals, may be more prevalent than the overt and extreme manifestations captured by typical survey questions. For example, $60 \%$ of CAPS respondents in 2006 reported that they had personally heard other people saying nasty things about PLWHA. Unfortunately this question was asked only in 2006 so we do not know how this more subtle measure of stigma may have changed over time.

The significant increases in instrumental stigma and symbolic stigma are alarming - especially considering that the respondents were in an age group intensively targeted with HIV-prevention messages. In addition, the increases in stigma were measured over the same period during which South Africa started providing antiretroviral treatment through the public sector - a process that began in Cape Town in 2001. This suggests that AIDS prevention and treatment initiatives either had no effect on reducing stigma, or that any potential reduction in stigma achieved through these initiatives was overwhelmed by other factors. Recent qualitative research evidence even posits that antiretroviral treatment itself may increase certain dimensions of stigma (Roura et al., 2008). Participants in this study conducted in Northern Tanzania believed that individuals on antiretroviral therapy were spreading the disease because of increased sexual activity and mobility as they regained health, and they could not be physically identified as HIVpositive. Antiretrovirals were also said to cause gluttony, greed, aggressiveness and mental disorders.

The finding that individuals with better knowledge of HIV transmission in 2003 showed greater increases in instrumental and symbolic stigma is probably a product of the fact that individuals with better knowledge of HIV transmission in 2003 expressed significantly lower levels of stigma than others (Maughan-Brown, 2006), and hence changes in reported attitudes represent a greater shift in stigma for these respondents. This does not, however, explain why, despite having good knowledge of HIV, symbolic stigma and especially instrumental stigma (fear of HIV infection) increased for these individuals.

The analysis reported on in this paper found no evidence that direct contact with PLWHA decreased stigma towards the group. The nature of the interaction between the respondents and PLWHA is, however, not known. As mentioned earlier, Almeleh (2006) found that in Cape Town HIV status disclosure is most common when people are sick and have no choice other than to disclose to potential care-givers and assistants. Consequently, HIV/AIDS is so strongly associated with illness and death that people whose health has been restored by HAART are regarded by some as no longer being HIV positive (Almeleh, 2006). 
This suggests that in the minds of respondents, interactions with PLWHA probably refer to extremely sick individuals who were dying of AIDS rather than individuals who were living healthy, productive lives with HIV. Instead of normalising the disease, interactions with PLWHA when they are sick with AIDS might perpetuate associations between HIV and illness, perpetuate fears of HIV/AIDS, and perpetuate negative moral judgement towards those affected, i.e. perpetuate stigma.

This paper has identified two factors that potentially contributed to increased levels of stigma. The first is knowing someone who had died of AIDS. The public-sector provision of HAART had only reached $55.7 \%$ of those in need of treatment by 2006 (Nattrass, 2007). This meant that despite the HAART roll-out, the numbers of annual AIDS-related deaths increased between 2003 and 2006. It is thus to be expected that a significant number of respondents reported knowing someone who died of AIDS over this period. This may well have reinforced associations between HIV/AIDS and death, increased fears of HIV/AIDS and increased moral judgement towards those affected.

Second, increases in instrumental stigma were significantly associated with an increase in negative behavioural intentions towards PLWHA. It is reasonable to suppose that if individuals become more fearful of HIV infection over time their willingness to interact with PLWHA might decrease. This finding indicates the direct negative effect that increases in instrumental stigma may have for PLWHA. Given the negative association between knowledge about HIV and HIV-related stigma, we know that HIV education is necessary to reduce stigma (Boer \& Emons, 2004; Dias, Matos, \& Goncalves, 2006; Herek \& Capitanio, 1998; Maughan-Brown, 2006). There is also evidence that interacting with PLWHA is associated with increased fears of infection (Maughan-Brown, 2008). The findings in this paper, especially as stigma increased among individuals with good knowledge of HIV transmission, also suggest the need to weaken associations between HIV and death. This could be done by better educating people on how to avoid HIV infection and on the potential PLWHA now have to live long and healthy lives on HAART, and by steadily expanding the HAART roll-out.

Although the analyses of determinants of change in stigma controlled for several factors such as changes in education and knowledge about HIV transmission, they were limited in that the CAPS surveys did not include items to reflect all factors influencing stigmatising attitudes and behaviours e.g., media ads and HIVprevention campaigns.

In addition to the above caveat, a number of other potential limitations should be flagged before any conclusions are drawn. First, length constraints in the 2006 survey of CAPS resulted in the symbolic stigma index comprising only two questions. Given that symbolic stigma is a complex social phenomenon consisting of a range of different aspects, this could potentially weaken the reliability and validity of this index. Second, especially in the case of face-to-face interviews, stigma may be underestimated as a result of social desirability bias. Third, questions probing behavioural intentions are almost always hypothetical in nature. This is problematic because many people might not know how they would act in certain situations.

\section{Conclusion}

Stigma is a complex social construct that is influenced by many factors. Assumptions that HIV-related stigma will decrease as soon as treatment is provided should not be automatically transferred to expectations about the effect on stigma of a particular intervention. Instead, it is necessary to use a multi-dimensional approach to monitor stigma over time in order to understand how stigma changes and what shapes such changes. The increases in HIV-related stigma identified by this research paper highlight the imperative for renewed efforts to be made to reduce stigma, perhaps through interventions to weaken the association between HIV/AIDS and death, to reduce fear of HIV/AIDS, and to recast HIV as a chronic manageable disease. One such intervention could be the facilitation of greater contact between the general population and individuals who are coping well with their HIV status and living otherwise healthy, productive lives. The identified increases in stigma highlight the importance of further research to determine the factors influencing such changes, especially if these undermine any positive gains achieved through treatment provision.

\section{References}

Abadía-Barrero, C., \& Castro, A. (2005). Experiences of stigma and access to HAART in children and adolescents living with HIV/AIDS in Brazil. Social Science \& Medicine, 62, 1219-1228.

Actuarial Society of South Africa (ASSA). (2005). ASSA2003 HIV/AIDS projection models. Available at: http://www.assa.org.za.

Aggleton, P., \& Parker, R. (2002). World AIDS Campaign 2002-2003. A conceptual framework and basis for action: HIV/AIDS stigma and discrimination. Switzerland: UNAIDS.

Aggleton, P., Parker, R., \& Maluwa, M. (2003). Stigma, discrimination and HIV/AIDS in Latin America and the Caribbean. Inter-American Development Bank. Available at: http://www.iadb.org/sds/doc/SOC130Stigma_and_AIDS.pdf.

Almeleh, C. (2006). Why do people disclose their HIV status? Qualitative evidence from a group of activist women in Khayelitsha. Social Dynamics, 32(2), 136-169.

Boer, H., \& Emons, P. (2004). Accurate and inaccurate HIV transmission beliefs, stigmatizing and HIV protection motivation in northern Thailand. AIDS Care, 16(2), 167-176.

van Brakel, W. (2006). Measuring health-related stigma - a literature review. Psychology, Health \& Medicine, 11(3), 307-334.

Cao, X., Sullivan, S., Wi, Z., \& the China CIPRA Project 2 Team. (2006). Understanding HIV-related stigma and discrimination in a "blameless" population. AIDS Education and Prevention, 18(6), 518-528.

Coetzee, D., Hildebrand, K., Boulle, A., Maartens, G., Louis, F., Labatala, V., et al. (2004). Outcomes after two years of providing treatment in Khayelitsha, South Africa. AIDS, 18(6), 887-895.

Dias, S., Matos, G., \& Goncalves, A. (2006). AIDS-related stigma and attitudes towards AIDS-infected people among adolescents. AIDS Care, 18(3), 208-214.

Farmer, P., Léandre, F., Mukherjee, J., Claude, M., Nevil, P., Smith-Fawzi, M., et al. (2001). Community-based approaches to HIV treatment in resource-poor settings. Lancet, 348, 404-409.

Hamra, M., Ross, M., Orrs, M., \& D'Agostino, A. (2006). Relationship between expressed HIV/AIDS-related stigma and HIV-beliefs/knowledge and behaviour in families of HIV infected children in Kenya. Tropical Medicine and International Health, 11(4), 513-527.

Herek, G. (2002). Thinking about AIDS and stigma: a psychologist's perspective. Journal of Law, Medicine and Ethics, 30, 594-607.

Herek, G., \& Capitanio, J. (1997). AIDS stigma and contact with persons with AIDS: effects of direct and vicarious contact. Journal of Applied Social Psychology, 27(1), $1-36$.

Herek, G., \& Capitanio, J. (1998). Symbolic prejudice or fear of infection? A functional analysis of AIDS-related stigma among heterosexual adults. Basic and Applied Social Psychology, 20(3), 230-241.

Herek, G., \& Capitanio, J. (1999). AIDS stigma and sexual prejudice. American Behavioural Scientist, 42, 1126-1143.

Herek, G., Capitanio, J., \& Widaman, K. (2003). Stigma, social risk, and health policy: public attitudes toward HIV surveillance policies and the social construction of illness. Health Psychology, 22(5), 533-540.

Kalichman, S., \& Simbayi, L. (2006). HIV testing attitudes, AIDS stigma and voluntary HIV counselling and testing in a black township in Cape Town, South Africa. Sexually Transmitted Infections, 79, 442-447.

Maughan-Brown, B. (2006). Attitudes towards people with HIV/AIDS: stigma and its determinants amongst young adults in Cape Town, South Africa. South African Review of Sociology, 37(2), 165-188.

Maughan-Brown, B. (2008). A multidimensional quantitative evaluation of HIV/ AIDS-related stigma in Cape Town, South Africa. Unpublished doctoral thesis, University of Cape Town, Cape Town, South Africa.

Nattrass, N. (2007). Mortal combat. University of Kwa-Zulu Natal Press.

Preston-Whyte, E. (2003). Contexts of vulnerability: sex, secrecy and HIV/AIDS. African Journal of AIDS Research, 2(2), 89-94.

Rao, D., Kekwaletswe, T., Hosek, S., Martinez, J., \& Rodriguez, F. (2007). Stigma and social barriers to medication adherence with urban youth living with HIV. AIDS Care, 19(1), 28-33.

Roura, M., Urassa, M., Busza, J., Mbata, D., Wringe, A., \& Zaba, B. (2008). Scaling up stigma? The effects of antiretroviral roll-out on stigma and testing. Early evidence from rural Tanzania. Sexually Transmitted Infections. doi:10.1136/ sti.2008.033183. 
Shisana, O., Rehle, T., Simbayi, L., Parker, W., Zuma, K., Bhana, A., et al. (2005). The South African National HIV prevalence, HIV incidence, behaviour and communication survey. The Nelson Mandela Foundation. HSRC Press. Available at: http:// www.hsrcpress.ac.za/product.php?productid $=2134$.

Terwee, C., Bot, S., de Boer, M., van der Windt, D., Knol, D., Dekker, J., et al. (2007) Quality criteria were proposed for measurement properties of health status questionnaires. Journal of Clinical Epidemiology, 60(1), 34-42.

UNAIDS. (2006). AIDS epidemic update. http://data.unaids.org/pub/EpiReport/ 2006/2006_EpiUpdate_en.pdf.
Weiss, M., \& Ramakrishna, J. (2006). Stigma interventions and research for international health. The Lancet, 367, 536-538.

Weiss, M., Ramakrishna, J., \& Somma, D. (2006). Health-related stigma: rethinking concepts and interventions. Psychology, Health \& Medicine, 11(3), 277-287.

Whiteside, A. (2008). HIV/AIDS: A very short introduction. Oxford: Oxford University Press.

Wolfe, W., Weiser, D., Bangsberg, D., Thior, I., Makhema, J., Dickinson, D., et al (2006). Effects of HIV-related stigma among an early sample of patients receiving antiretroviral therapy in Botswana. AIDS Care, 18(8), 931-933. 